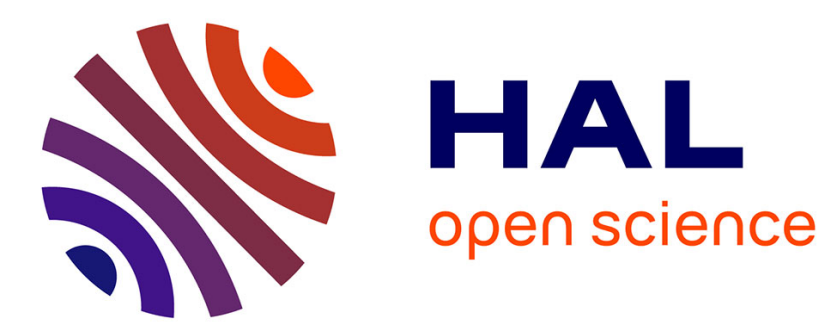

\title{
Algebraic Solutions of Newton's identities for cyclic codes
}

Daniel Augot

\section{To cite this version:}

Daniel Augot. Algebraic Solutions of Newton's identities for cyclic codes. 1998 Information Theory Workshop, Aug 1998, Killarney, Ireland. pp.49, 10.1109/ITW.1998.706411 . inria-00509468

\section{HAL Id: inria-00509468 https://hal.inria.fr/inria-00509468}

Submitted on 12 Aug 2010

HAL is a multi-disciplinary open access archive for the deposit and dissemination of scientific research documents, whether they are published or not. The documents may come from teaching and research institutions in France or abroad, or from public or private research centers.
L'archive ouverte pluridisciplinaire HAL, est destinée au dépôt et à la diffusion de documents scientifiques de niveau recherche, publiés ou non, émanant des établissements d'enseignement et de recherche français ou étrangers, des laboratoires publics ou privés. 


\begin{abstract}
This paper consider the use of Newton's identities for establishing properties of cyclic codes. The main tool is to consider these identities as equations, and to look for the properties of the solutions.

First these equations have been considered as necessary conditions for establishing non existence properties of cyclic codes, such as the non existence of codewords of a given weight.

The properties of these equations are studied, and the properties of the solution to the algebraic system are given. The main theorem is that codewords in a hamming sphere around a given word can be characterized by algebraic conditions. This theorem enables to describe the minimum codewords of a given cyclic codes, by algebraic conditions. The equations are solved using the Buchberger's algorithm for computing a Groebner basis.

Examples are also given with alternant codes, and with a non linear code.
\end{abstract}




\title{
Algebraic Solutions of Newton's identities for cyclic codes (extended abstract for submission)
}

\author{
Daniel Augot
}

August 12, 2010

\section{Introduction}

We consider words of length $n$ over $G F(q), n$ being prime to $q$. A primitive root $\alpha$ is fixed. The word $c=\left(c_{0}, \ldots, c_{n-1}\right)$ is identified with the polynomial $c_{0}+c_{1} X+\ldots+c_{n-1} X^{n-1} \bmod X^{n}-1$. The Fourier Transform of $c \in G F\left(q^{\prime}\right)^{n}$, denoted $\phi(c)$, is $A=\left(A_{0}, A_{1}, \ldots, A_{n-1}\right), A_{i}=a\left(\alpha^{i}\right), i=0 \ldots n-1$.

Let $c=\left(c_{0}, \ldots, c_{n-1}\right) \in G F\left(q^{\prime}\right)^{n}$. The locators of $c$ are $\left\{X_{1}, \ldots, X_{w}\right\}=$ $\left\{\alpha^{i_{1}}, \ldots, \alpha^{i_{w}}\right\}$, where $i_{1}, \ldots, i_{w}$ are the indices of non zero coordinates of $c$. The elementary symmetric functions of $c$, denoted by $\sigma_{1}, \ldots, \sigma_{w}$, are $\sigma_{i}=$ $(-1)^{i} \sum_{1<j_{1}<\ldots<j_{i}<w} X_{j_{1}} \cdots X_{j_{i}}, i=1 \ldots w$. The generalized Newton's identities hold: $\forall i \geq 0, \quad A_{i+w}+\sigma_{1} A_{i+w-1}+\ldots+\sigma_{w} A_{i}=0$.

These equations have been used for establishing contradictions. This way, the true minimum distance of BCH codes of length 244 and designed distance 59 and 61 have been found [2].

\section{Main Theorem}

TheOREM[1] Let $C$ be a cyclic code defined by the equations $A_{1}, \ldots, A_{l}=0$. Let $S_{C}(w)$ be the following system of equations:

$$
\begin{gathered}
A_{1}=\cdots=A_{l}=0 \\
A_{i+w}+\sigma_{1} A_{i+w-1}+\ldots+\sigma_{w} A_{i}=0, \quad i=0 . . n-1
\end{gathered}
$$

with indeterminates $\sigma_{1}, \ldots, \sigma_{w}, A_{0}, \ldots, A_{n-1}$. Let $A=\left(A_{0}, \ldots, A_{n-1}\right)$ be a solution to $S_{C}(w)$ (i.e. there exists $\sigma_{1}, \ldots, \sigma_{w}$ such that $\left(\sigma_{1}, \ldots, \sigma_{w}, A\right)$ is a solution), then $A$ is the Fourier transform of a codeword of weight $\leq w$. 


\section{Generalization to alternant codes and other}

Cyclic codes are the easiest to deal with, because of the many indeterminates which are zero in the system $S_{C}(w)$. However the theorem easily generalize to other codes, as long as we are able to define these codes by algebraic conditions on the coefficients of the Fourier transform of codewords.

Definition Let $C$ be a code in $G F\left(q^{\prime}\right)^{n}$ (or $\left.G F(q)^{n}\right)$. If there exists $l$ polynomials in $n$ variables $P_{1}, \ldots, P_{l}$, such that, for all $c \in G F\left(q^{\prime}\right)^{n}\left(\right.$ or $\left.G F(q)^{n}\right)$, $c$ belongs to $C$ if and only if $P_{1}\left(A_{0}, \ldots, A_{n-1}\right)=\ldots=P_{l}\left(A_{0}, \ldots, A_{n-1}\right)=0$, where $A=\phi(c)$, then the code has a spectral definition. The polynomials $P_{1}, \ldots, P_{l}$ are the code spectral equations.

Our result, which is a generalization of a case of a cyclic code [3], is the following theorem:

TheOREM Let $C$ be a code defined by the spectral equations $P_{1}, \ldots, P_{l}$. Let $S_{C}(w)$ be the following system of equations:

$$
\begin{gathered}
P_{1}\left(A_{0}, \ldots, A_{n-1}\right)=\cdots=P_{l}\left(A_{0}, \ldots, A_{n-1}\right)=0 \\
A_{i+w}+\sigma_{1} A_{i+w-1}+\ldots+\sigma_{w} A_{i}=0, \quad i=0 . . n-1
\end{gathered}
$$

with indeterminates $\sigma_{1}, \ldots, \sigma_{w}, A_{0}, \ldots, A_{n-1}$. Let $A=\left(A_{0}, \ldots, A_{n-1}\right)$ be a solution to $S_{C}(w)$ (i.e. there exists $\sigma_{1}, \ldots, \sigma_{w}$ such that $\left(\sigma_{1}, \ldots, \sigma_{w}, A\right)$ is a solution), then $A$ is the Fourier transform of a codeword of weight $\leq w$.

Now we consider alternant codes. Let $\underline{\alpha}=\left(\alpha_{0}, \ldots, \alpha_{n-1}\right) \in G F\left(q^{\prime}\right)^{n}$ be distinct elements in $G F\left(q^{\prime}\right)$, and let $\underline{v}=\left(v_{0}, \ldots, v_{n-1}\right)$ be nonzero elements in $G F\left(q^{\prime}\right)$. The generalized Reed Solomon code, $G R S_{k}(\underline{\alpha}, \underline{v})$, is the code whose codewords are $\left(v_{0} F\left(\alpha_{0}\right), \ldots, v_{n-1} F\left(\alpha_{n-1}\right)\right)$, for all $F \in G F\left(q^{\prime}\right)[X], \operatorname{deg} F<k$.

The alternant code $\mathcal{A}_{k}(\underline{\alpha}, \underline{v})$ is the $G F(q)$-subfield sub-code of $G R S_{k}(\underline{\alpha}, \underline{v})$. We show how the alternant codes when $v$ is the set of $n$-th root of unity, where are defined with spectral equations.

Next, we consider the Preparata code of length 15 can be defined (Blahut) by spectral equations. The code is binary, of length 15 , and its codewords satisfy

$$
\begin{aligned}
A_{1} & =0 \\
A_{3} A_{5} & =0 \\
\left(A_{3}^{5}-1\right)\left(A_{5}^{3}-1\right) & =0 .
\end{aligned}
$$

which are spectral equations. This example is worked out.

\section{References}

[1] D. Augot. Description of Minimum Weight Codewords of Cyclic Codes by Algebraic Systems. In Finite Fields and their Applications vol. 2, 1996. 
[2] D. Augot and P. Charpin and N. Sendrier Studying the Locator Polynomial of Minimum Weight Codewords of BCH codes. In IEEE Transaction on Information Theory vol. 38, year 1992.

[3] D. Augot. Algebraic characterization of minimum weight codewords of cyclic codes. In Proceedings IEEE, ISIT'94, Trondheim, Norway, June 1994.

[4] F.J. Mac Williams and N.J.A. Sloane. The Theory of Error Correcting Codes. North-Holland, 1986. 